\title{
Known Inherent Risk of Device
}

National Cancer Institute

\section{Source}

National Cancer Institute. Known Inherent Risk of Device. NCI Thesaurus. Code C91878.

Reported adverse event known and documented in the labeling (including both short or long term known complications or adverse reactions). 